\begin{tabular}{l} 
RCCS \\
\hline Annual Review
\end{tabular}

\section{RCCS Annual Review}

A selection from the Portuguese journal Revista Crítica de Ciências Sociais

$2 \mid 2010$

Issue no. 2

\title{
The Phonographic Industry and the Recorded Music Market: A Long Misunderstanding
}

\section{Paula Abreu}

Translator. Sheena Caldwell

\section{OpenEdition}

\section{Journals}

Electronic version

URL: http://journals.openedition.org/rccsar/220

DOI: $10.4000 /$ rccsar.220

ISSN: 1647-3175

Publisher

Centro de Estudos Sociais da Universidade de Coimbra

\section{ELECTRONIC REFERENCE}

Paula Abreu, « The Phonographic Industry and the Recorded Music Market: A Long Misunderstanding ", RCCS Annual Review [Online], 2 | 2010, Online since 01 October 2010, connection on 30 April 2019. URL : http://journals.openedition.org/rccsar/220 ; DOI : $10.4000 /$ rccsar.220 


\section{Paula Abreu}

Centre for Social Studies and School of Economics, University of Coimbra

\section{The Phonographic Industry and the Recorded Music Market: A Long Misunderstanding ${ }^{*}$}

Drawing on research into the Portuguese phonographic industry, this article addresses the crisis which the industry is currently facing, with the aim of showing how the history of the phonographic field has, from the outset, been marked by various doubts and uncertainties emerging from disputes over a number of objects. It also shows that these doubts have always led to the reinvention of the conventions that have shaped the activities of this organisational and commercial field.

Based on an analytical perspective that draws on the theoretical contributions of institutionalist economic sociology (Powell and DiMaggio, 1991; Fligstein, 1996 and 2001) and the economic sociology of conventions (Boltanski and Thévenot, 1991 and 1999; Thévenot, 2002), it discusses the dilemmas experienced by the industry, exploring the hypothesis that these have emerged as a result of the different orders of worth mobilised to coordinate activities in the phonographic field.

Keywords: Phonographic industry; history; uncertainty; *coordination; orders of scale.

In literature on the culture industries and the phonographic industry in particular, very few works consistently address the ways in which these fields of activity and their respective markets have been established. In fact, in both sociology and economics it is common to encounter the use of such abstract concepts as "capitalist mode of industrial production" and "market production," but their analytical productiveness depends, to a great extent, on the way they are operationalized so as to enable a definition of the most relevant aspects of each object. In the case of the phonographic industry, such operationalization demands that we examine the ways in which these activities have historically developed, creating a field which is simultaneously industrial, commercial and cultural.

An attempt to understand the conditions under which a new set of activities, equipment and objects emerged in the late $19^{\text {th }}$ and early $20^{\text {th }}$ centuries, and the processes by which their use and exchange values were established, would appear to be an appropriate strategy to adopt in order to avoid reproducing relatively simplistic views of such a complex universe.

In pursuing this research strategy I have been inspired by the institutionalist perspectives in economics and sociology, specifically the theses of Paul DiMaggio and Walter Powell concerning organizational fields and Neil Fligstein concerning markets (Powell and DiMaggio, 1991; Fligstein, 1996; Fligstein, 2001). The analytical focus of these theories relativizes the contribution of technical and market rationales to the development of economic activities,

\footnotetext{
*Article published in RCCS 85 (June 2009).
} 
showing how they combine with a series of other conventional rationales underlying the institutionalization of organizational fields and their markets. In order to identify the connections between these various rationales it is essential to resort to a historical analysis of the constitution of these fields. This is the analytical perspective I have sought to develop in studying the phonographic industry, with the aim of understanding the processes involved in the formation of the institutional principles that have come to shape activities in this industry, the organisation of its companies and the workings of its markets. The adoption of this perspective also allows for dialogue with Pierre Bourdieu's theory of fields, by applying the structuralist and genetic approach that he uses to describe cultural fields to a culture industry (Bourdieu, 1996).

In fact, a historical approach to the phonographic industry reveals, firstly, the diversity of the objects that have been the target of struggles and negotiations between the various agents intervening in the field. Secondly, it shows the distinctive nature of these objects, which cannot be limited to the economic or cultural spheres, as Pierre Bourdieu proposes. In this sense, history shows how the institution of phonographic activities as an organised industrial and cultural field is the result of a struggle for various kinds of resources and the negotiation of a variety of conventions. It is these conventions, shared by the different actors in the field (the phonographic companies, professional unions, associations for managing property rights, company associations, etc.), which enable actions to be coordinated so that its products can be manufactured, distributed and consumed. Nevertheless, the processes involved in defining these conventions have always been complex and prolonged, reflecting the mobilisation of different modes of justification and regimes of coordination or, in Luc Boltanski and Laurent Thévenot's terms, different orders of worth (ordres de grandeur). These authors identify at least six regimes - inspiration, domestic, fame or opinion, civic, industrial and market - each involving the link between the order of worth relevant to the action, tests or proof of this worth, and the corresponding orderings or hierarchies, as well as the pertinent social actors, in addition to the objects and material and technical mechanisms that give material form to each order (Boltanski and Thévenot, 1991 and 1999; Thévenot, 2001 and 2002). Reflecting the articulation between different regimes of coordination and justification, the establishment of conventions in the field of the phonographic industry reveals disputes and agreements concerning not only mercantile and technical matters associated with the industrial order and the market, but 
also struggles and negotiations over cultural contents and formats, related to principles of the inspiration order; controversies over forms of presenting and publicising companies, phonograms and artists, related to logics inherent to the order of fame; and debates on definitions of property and forms of public regulation of copyrights, connected with the civic order.

The main aim of this paper is precisely to show how the history of the phonographic industry and its markets has, from the outset, been marked by various doubts and uncertainties arising out of disputes over different objects, and how these doubts have always led to the reinvention of the conventions that have come to shape the activity of this organisational and mercantile field. In the final part of the text, I also seek to describe the current crisis in the phonographic industry as yet another instance of critical uncertainty in which the actors involved confront major issues concerning the definition of the common value of phonograms and how this value may continue to coordinate a chain of activities that range from the creation to the use and enjoyment of recorded music.

\section{From early uncertainties to the first conventions}

In the abundant literature on the history of sound recording, Thomas Edison and his invention, the phonograph, are usually identified as the founding figure and event in the phonographic industry. The phonograph, a device invented in Edison's laboratories in 1877, was indeed the first piece of sound recording equipment formally recognized by means of a patent registered in 1878 . However, within the context of understanding the development of the phonographic field, attempting to define a founding event or figure is an equivocal strategy. An alternative and more fruitful approach would be to adopt the suggestion made by Andre Millard, who locates the origins of what we nowadays know as the phonographic industry within the context of the communications revolution (Millard, 2005: 17). This enables us to examine how, starting from a relatively undifferentiated context of technological innovation and industrial applications, the process that led to the formation of a specific universe of industrial and cultural activities gradually evolved.

The communications revolution had, in fact, begun in the mid $19^{\text {th }}$ century with the invention and development of the telegraph. With the application of this technology, the quantity and speed of communications increased and the recording and reproduction of sound became the subject of new research. In 1876, Alexander Bell registered the patent for 
the telephone, and the following year Thomas Edison announced the invention of the phonograph. However, Bell and Edison were only two of many individuals who were exploring and testing new techniques and technologies in the fields of sound, electricity and communications. ${ }^{1}$ The ideas that Edison applied to the development of the phonograph were explored by many other inventors of the time, who understood the techniques associated with electricity and sound and, specifically, their applications to the telegraph and the telephone - such as Charles Tainter and Chichester Bell, who developed the graphophone, ${ }^{2}$ and Émile Berliner, the inventor of the gramophone.

These inventions took place within an effervescent context of technological innovation and creativeness in the 19th century, as well as sharp industrial development, particularly in England and the United States, and this suggests the arbitrariness of attributing the origins of the phonographic industry to the emergence of the first sound recording devices. From the outset, there was an appreciable disparity between the uses attributed by inventors to new equipment and those that were gradually reinvented as a result of the relationship between technical and technological constraints and the universe of users (inventors, publicists, traders and the public).

In this respect, Edison is a prime example of this discrepancy. In fact, as Sophie Maisonneuve shows, the famous inventor defined an ample script for the phonograph, placing it within a context similar to that of the other inventions associated with communications, i.e. as a device meant to preserve and reproduce sound and therefore to be used for a variety of clerical, archival and educational purposes, an extension of the telephone, whose applications would be particularly useful in the sphere of clerical work (Maisonneuve, 2002: 49). Although this script was sufficiently open-ended to admit the reconfigurations that came to result from the appropriation of the phonograph, it still reveals the huge gap between the inventor's concept of the machine and its future uses.

\footnotetext{
${ }^{1}$ Like Millard, Oliver Read and Walter L. Welch also believe that the history of the modern phonograph in fact begins with the invention of the telegraph and research into telegraph and telephone communications. Indeed, the main inventors of the first "talking machines" (Edison, Bell and Berliner) had all been involved in this research (Read and Welch, 1976: 1-10).

${ }^{2}$ The graphophone was developed by Tainter and Bell in Alexander Bell's Volta laboratories, on the basis of Edison's phonograph technology, introducing technical and technological improvements in the type of cylinder used to record sound. A. Bell suggested to Edison that they should jointly develop this resource but the latter refused, returning to his work on the phonograph and perfecting it on the basis of Tainter and C. Bell's experiences with the graphophone (Millard, 2005: 17-36).
} 
The technological and technical limitations on actual sound recording prevented the phonograph from immediately becoming a communications device in the sense in which Edison had envisaged it. However, the presentation of the equipment at exhibitions, trade fairs and laboratory exhibitions, as well as in the streets and in commercial establishments, showed its entertainment potential. Besides displaying curiosity about the equipment and its potential uses, the public revealed a special liking for the sound that could be heard. The success of these exhibitions helped redefine the expected uses of the "talking machine" and this raised new problems in terms of operating the equipment, the possibilities of sound reproduction (without wearing out the support and the sound recording) and the mass production of sound recordings for recreational purposes.

The problems presented to the inventors of sound recording equipment whilst they tested out its uses in public explain the lapse in time between the invention of the phonograph and the industrial production and commercial development of both the equipment and the sound recordings required for its performance. In fact, it was only in the first years of the $20^{\text {th }}$ century that the main difficulties involved in the industrial production of these fragile devices were overcome and the three main companies responsible for their production began operating in the United States of America - The Edison Phonograph Company, founded by Thomas Edison, the Victor Talking Machine, founded by Eldridge Johnson and Émile Berliner, and the Columbia Phonograph Company, an agent of the by then defunct North American Phonograph Company, created by Joseph Lippincott to produce the first models of Edison's phonograph (Millard, 2005: 50). As Millard states,

The Edison, Victor and Columbia companies were known as the Big Three. They dominated the market with their strong patent position and extensive manufacturing plant. After many years of hard lessons and repeated failure, they had finally applied the American system of manufacture with interchangeable parts to the talking machine". (Millard, 2005: 50)

Despite some equivocation over the initial uses envisaged for the "talking machines," Pekka Grunow and Ilpo Saunio (1999: 1-7) note that by the beginning of the $20^{\text {th }}$ century Edison had already realised that the phonograph was primarily a "music box" and by then was dedicating his time to the production of recorded cylinders, launching a new phonograph model destined for household use in America (known as the home phonograph). Meanwhile, the Berliner gramophone had undergone major improvements, particularly with the contributions of Eldridge Johnson. It was Johnson who designed the 
motor that was attached to the gramophone, enabling it to work autonomously. He also invented the process for recording masters onto wax discs, thus improving the quality of the recordings and enabling recorded discs to be mass produced.

Thus, although many technical and technological limitations still remained in terms of equipment (the phonograph and the gramophone), affecting both the supports (cylinders and records) and the actual sound recording techniques (still acoustic), by the early years of the $20^{\text {th }}$ century the technical conditions were in place for the development of the phonographic industry.

Nevertheless, various other conditions required to form true markets were still lacking. The first of these involved matching this offer with a potential demand, sustained by habits and social practices for integrating and using the new objects - the equipment and the sound recordings. In fact, as Sophie Maisonneuve suggests, the history of the phonograph/gramophone and the phonographic industry has centred on the technological, industrial and economic aspects and neglected uses and users (Maisonneuve, 2001b: 91). Yet, it was the process of transforming the new equipment into new musical media and the establishment of a new music culture that allowed the activities of the industry and the phonographic market to be consolidated, from the 1920s onwards.

In the first two decades of the last century, economic and technological conditions combined to enable the price of the equipment and the sound recordings to be lowered and the volume and diversity of the recorded musical repertoire to expand. The main technological innovation was the introduction of the microphone, which not only led to significant improvements in the sound quality of the recordings, but also enabled the recording of wider music ensembles, a greater range of instruments and, because of this, a more diverse repertoire. At the same time, advances in technology for supports, specifically the introduction of the double-sided record and the extension of the recording time on each side, enhanced the effects of recording with a microphone, leading to a substantial increase in the number of commercially developed sound recordings. In turn, the development of portable gramophones increased the opportunities for listening to records. This series of innovations explains, to a great extent, the fact that the gramophone became established as the sound reproduction device par excellence, the musical medium to which Maisonneuve refers (2001a), definitively supplanting the phonograph. 
These new technological conditions were reflected in the way in which consumers developed a series of new material and aesthetic uses for music, the equipment and the records. The work of Sophie Maisonneuve shows how listening to records in the home involved a new way of consuming and listening to music. ${ }^{3}$ Consumption took place in a domestic environment and involved careful operations for handling the gramophone and the records, leading to the development of specific skills and habits. It was a form of consumption that turned music into a material commodity, divested records of their luxury status and transformed them into goods that could be collected. In short, it was a form of consumption that changed the ways in which people related to music, enabling works to be listened to repeatedly, recordings to be compared and aesthetic-musical knowledge and emotional experiences to be accumulated, stimulating a form of listening in which the main variable was the sound. It was "aural listening" which took place in the private space of the home and favoured the construction of intimate universes of aesthetic enjoyment (Maisonneuve, 2001a).

The creation of this new musical culture and the establishment of the gramophone as the prime musical medium had a particular cultural significance within the context of the establishment of the new industry. These processes specifically involved the form of musical expression which, at the time, had the greatest aesthetic and social value - "classical" music, the musical repertoire which had come to constitute the musical canon par excellence throughout the $18^{\text {th }}$ and $19^{\text {th }}$ centuries (DeNora, 1995; Weber, 1989). Its assimilation into the recorded musical repertoire contributed greatly towards providing cultural recognition for the phonographic industry, both in Europe and the United States of America. ${ }^{4}$ However, as Maisonneuve (2002) and Chanan (1995) note, the transformation of the gramophone into a

\footnotetext{
${ }^{3}$ By resorting to testimonials that appeared in numerous publications in England and France at the beginning of the $20^{\text {th }}$ century, Maisonneuve (2002) shows how music lovers gradually developed technical and operational skills that stimulated new aesthetic dispositions for listening to music. She also shows how music critics contributed to this process by assuming a pedagogical role and how companies adapted to the situation by publishing equipment manuals and catalogues presenting and describing the recordings that had been released.

${ }^{4}$ Also from the point of view of the production of phonographic recordings, which David Morton terms the recording culture (Morton, 2000: 13-47), although popular music has been the greatest source of growth in the phonographic industry throughout its history, classical music was the form of music which had the greatest influence on technological changes and practices in the recording studios during the formative years of the industry: "Recording company executives sometimes revealed that their catalog of classical recordings was mainly for prestige, not money. The influence of high culture music in the development of recording technology greatly exceeded the economic importance of classical record sales or the size of the audience for such music. Indeed, high fidelity and high culture played the most important roles in establishing the engineering basis of sound recoding, and continue to exercise an influence today" (Morton, 2000: 16-17).
} 
new musical medium also involved the popular music styles that had exploded onto the scene from the middle of the $19^{\text {th }}$ century onwards, with the development of new forms of leisure activities. Through records, these expressions of popular music conquered the public arena and became associated with new forms of social and leisure activities.

In addition the creation of the demand that was essential for the establishment of phonographic markets, certain other conditions limited the formation of industrial fields focussing on the markets for phonographic goods. One of these limitations was associated with the nature of the goods produced by the industry itself. As Simon Frith states (1988: 1123 ), at the end of the $19^{\text {th }}$ and beginning of the $20^{\text {th }}$ centuries, the phonographic industry was primarily a hardware rather than a software industry, integrated into the electricity industry. However, as Michael Chanan suggests (1995: 23-36), the specific nature of the industry was based on a technological association that caused its products to have a dual form: the sound recording/reproduction equipment - the phonograph or gramophone - and the sound recordings - the cylinder or record. Moreover, the sounds produced by these objects could not exist without equipment, supports and sound recordings. Consequently, the manufacturers of sound recording and sound reproduction equipment had, by necessity, to add the production of content to their business activities: "Since you cannot have one without the other, this gave rise to a general principle, namely that the manufactures of any kind of hardware have to concern themselves with the production of the appropriate software without which hardware has no market" (Chanan, 1995: 32).

The phonographic companies soon began to realise how vital the production of sound recordings was to the success of equipment production, but they still had to overcome several obstacles. In this context, as previously stated, the system created by Berliner and later perfected and developed by Eldridge Johnson proved the most flexible response to the requirements for reproducing sound recordings. Records, unlike cylinders, could already be reproduced from a master recording and therefore manufactured in sufficient quantities to meet market demand (Millard, 2005: 48-49). Berliner and Johnson secured another advantage by pioneering the dispatch of sound recording technicians to Europe to expand the range of music recordings available to their companies. The best known of these technicians were the famous Gaisberg brothers, who were responsible for countless recordings made in Europe and various other places throughout the world, which appeared in the early catalogues of the Gramophone Company (in England) and the Victor Talking 
Machine (in the United States). The musical sensibility of Fred Gaisberg enabled the two companies to strategically develop their catalogues, filling them with recordings of the most important works and performances of classical music as well as popular music themes from a variety of locations all over the world.

Edison had greater difficulty in convincing himself of the need to increase the number of sound recordings, being more concerned with the technical and technological improvements of the phonograph, its cylinders and the quality of the sound reproduced. He had a more conservative vision of music production and recording, focussing on the material devices and downplaying the fact that their technical and commercial value was closely linked to the specific musical content of the sounds recorded. Later, Edison's miscalculation would become a decisive factor in the decline of his phonographic company and even in its eventual closure in 1928.

The importance of the cultural content of phonographic activities became so evident that the actual composers and writers and the publishers of their printed works demanded that copyright regulations be extended to the sphere of "mechanical music." The dispute was settled by individual states, initially through the courts and later by legally establishing the property rights of authors and composers for phonographically recorded works through national legislation and international agreements - namely, the Berne Convention, signed in Paris in 1890 and revised in Berlin in 1908 (Chanan, 1995: 23-36). ${ }^{5}$

In this brief survey of certain aspects of the early history of the phonographic field, i.e. the period of its organizational establishment, I have attempted to highlight the multiple ambiguities that marked these early years. In order to resolve them, agreements had to be negotiated regarding the regimes of justification to be adopted. These ambiguities emerged in the context of activities guided by two dominant orders of worth: the industrial order underlying the activity of invention, which characterised the $19^{\text {th }}$ century, producing a vast number of new technical artefacts (the phonograph, for example); and the mercantile order, connected to the production of those artefacts for the market. The appearance of a new artefact such as the phonograph and its orientation towards the market demanded a

\footnotetext{
${ }^{5}$ Michael Chanan discusses the various legal proceedings that were set in motion even before the amendments to the Berne Convention in 1908, and which had different outcomes. In England, in 1899, the sheet music publishers lost their cases, whereas in France, in 1905, the courts ruled against the unauthorized reproduction of songs and music, and in Italy, in 1906, the Italian Society of Authors and Composers managed to win, through the courts, the right to royalties from the sale of records (Chanan, 1995).
} 
negotiation over its relevant uses. This was a complex negotiation since it involved not only design and production specialists and market professionals, but also potential users and intermediaries of these relationships.

In this case, the negotiation over the regime of justification of uses led to the mobilization of another order of worth: inspiration. Having been introduced in the coordination of uses of the phonographs, this order had an impact on the production and commercialization of the artefacts, leading to adjustments in the industrial and market activities related to them. The interconnection of these particular activities involved, in the same field of action, social actors and objects as diverse as the regimes of justification mobilized for their coordination, and led to the constitution of a specific field of activity - the phonographic industry field. As it developed, it progressively incorporated actors and objects that were initially outside this universe and that brought in new orders of worth. Authors and composers were among the first to be included in this field through their poems and compositions, which were indispensable for the production of musical recordings. Their entrance into the arena implied contention over new modes of action, now guided by the civic order, so as to protect the property rights of creators and thus also artistic activities.

\section{Contemporary ambiguities and the dissolution of conventions}

From the early days to the present day, many other sources of ambiguity and uncertainty have emerged, including: i) the relationship with the consumers of records, mediated from the 1920s onwards by new objects and activities (radio sets and radio broadcasting), and from the 1950s onwards by TV sets and TV broadcasting; ii) the musical styles of phonographic productions and recordings, which after the introduction of long-playing records took the shape of albums, with a coherent narrative of musical themes; iv) the nature of the recording techniques and technologies made available first to musicians and performers and later to consumers; v) the property rights associated with recorded musical works - not just authors' rights but also rights related to these, claimed by and granted to performers and producers; and so on and so forth. On several occasions, these uncertainties have given rise to major disputes between the actors in the field and to the reinvention of existing agreements or the negotiation of new ones, which introduced new orders of worth, in order to ensure the survival of their common activities. 
Since the 1980s, however, uncertainties have emerged much more rapidly. The development of digital technologies and their introduction into the sphere of recorded music, followed by the integration of digital systems and information and communications technology have had radical and multiplying consequences for the phonographic universe. In a short space of time, the conditions for creating music and for its phonographic production, distribution and consumption have changed.

In the early 1980s, the development of digital synthesisers and of the first musical instrument digital interface (the MIDI) as well as the appearance of the new digital recording supports (compact discs) radically influenced the nature of the phonographic industry and helped to redefine the use values and forms of music consumption.

Synthesisers first appeared in the mid 1970s when the musical instrument industry began to commercialize instruments equipped with memory devices that could store sound programmes. The development of digital technologies extended the potential of these devices and introduced new ways of working with synthesised sounds, such as the famous samplers.

The development and commercialisation of digital samplers, whether as separate hardware items or as software for computers, transformed digital techniques into operations that were accessible to musicians. As samplers could work with any type of prerecorded sound, their use introduced new practices into the creation and production of music - the practice of sampling. This is a form of musical quotation whereby composers incorporate any pre-recorded sound into a new recording (Katz, 2004: 139).

The popularisation of the use of digitalised sounds in music production revealed the convenience of linking the different synthesiser models, leading to efforts to standardise digital signals through the design of an interface for digital instruments - the Musical Instrument Digital Interface (MIDI). The development of this electronic protocol began in 1981, through a series of informal contacts established between representatives of the major digital sound equipment manufacturers, and the first version of the interface (the MIDI Specification 1.0) appeared on the market in the summer of 1983.

The MIDI made it possible to connect a plethora of equipment, ranging from synthesisers to classical musical instruments, through digital language. In addition to providing a communications platform for different music production devices, the MIDI system also 
facilitated the development of new forms of composition, mixing and editing, in which the computer played a key role.

By the 1990s, the first multitrack digital recorders equipped with mixers and editing applications had begun to appear on the non-professional consumer markets. However, the production of masters for commercial release still depended on the skills of recording studio professionals. Nevertheless, improvements to IT systems, hardware and software enabled personal computers to function as digital audio workstations (DAWs). These applications transformed computers into versatile digital recorders (Millard, 2000: 382), equipped to operate in conjunction with other devices, due to the popularisation of the MIDI system. The diffusion of DAWs, together with the popularity of the MIDI system, digital synthesisers and samplers, had a significant impact on the ways in which music production was organised. In the mid 1990s it was possible to set up a home studio relatively cheaply, with technical and technological resources similar to those found in a professional studio.

These changes had a significant impact on the studios and the professionals who worked in them, who began to lose the status they had achieved within the world of popular music from the seventies and eighties onwards. At the time, the introduction of multitrack recorders and the development of mixing and editing techniques had given them a central and autonomous role in music production, to the detriment of the musicians themselves (Théberge, 1997: 217). From this point onwards, the studios assumed the status of collective facilities for the composition and production of music, coordinated by music producers whose authority was based on the forms of mediation they developed between musicians, technicians, devices, publishers and the public (Hennion, 1989).

Digital technologies enabled musicians to set up home studios dedicated to musical creation, experimentation and composition. In this way, musicians regained their status as creators, escaping from the control exercised by producers and sound engineers. Professional studios did not disappear, but lost their pre-eminence as collective creative facilities, often playing a complementary role in the final production of music.

From the cultural point of view, technological change also had a significant impact on musical creation, multiplying the possibilities of some of the creative trends that had already emerged in the 1970s and that were intensively explored in the following two decades. Rap was one of these trends. A musical genre rooted in Hip Hop culture (an African-American 
street subculture), it emerged in the South Bronx, New York, in the 1970s, involving music, dance and graffiti.

The main features of Rap - the combination of a vocal narrative delivered in time to an electronic background rhythm in which the cadence of the voice and the musical beat work together ${ }^{6}-$ are directly related to its cultural roots and to its association with a form of dance music (Rose, 1994: 1-20). The beat of Rap music is achieved by using techniques developed by DJs in the mid-1970s in New York, Chicago and Washington, D.C. clubs and discotheques:

The beat in rap music is provided via a method known as 'scratch mixing', in which a dualturntable record player, originally developed to provide a continuous sequence of dance tracks in discotheques and nightclubs, itself becomes a musical instrument. Using one turntable to provide the rhythm, achieved through the manual manipulation of a record so that a selected sequence of bars is continually replayed, the DJ then uses the second turntable to mix in snatches of sound and instrumental themes from other records. (Bennett, 1999: 78-79)

Through the use of these techniques and fragments of pre-recorded music one of the key elements of this style of music is produced - a new type of percussion, as Teresa Fradique calls it (2003: 39).

Rappers initially used a creative method that depended on mechanical processes for splicing and recomposing sounds, but the arrival of digital technology offered them many resources for the creation of their own musical rhythms. Moreover, this was not only the case with rappers. DJs also explored this equipment in order to compose other forms of music, such as House and Techno.

In fact, whereas in New York the techniques developed by DJs were appropriated by the Hip Hop street subculture to create Rap, in Chicago they were developed within the context of the dance clubs themselves, giving rise to House music, whose name comes from one of the most popular clubs in the city - the Warehouse Club (Langlois, 1992). At the centre of the House music scene was the DJ, a professional whose role had developed over the 1970s and 80s until s/he was no longer merely responsible for selecting and changing records but had become a kind of musician (Langlois, 1992: 230). By the end of the 1970s, DJs were using a particular technique to spin records - known as blend mixing - in which fragments of music recorded on vinyl discs were mixed using a double deck to produce new sounds and

\footnotetext{
${ }^{6}$ The acronym itself echoes this particular rhythmic combination of voice and beat: RAP stands for Rhythm and Poetry (Fradique, 2003: 39).
} 
musical textures and even new pieces of music. The style of the North-American DJs quickly became popular with DJs in Europe and the rest of the world, who went on to develop their own mixing techniques. In this way, House began to influence the dance music of the 1980s and 90s.

Another dance music influence was Techno, a form of electronic music composed using computers which originated in Düsseldorf (Germany) through the work of a group called Kraftwerk. The music of Kraftwerk became popular with DJs in Chicago and other US cities, and they began adding these electronic sounds to their mixes. Digital technologies, introduced in the 1980s, influenced not only these new forms of music but also the experiments of the pioneers of what Andy Bennett has termed electro-pop (Bennett, 2001: 118-135).

Computers, samplers and the MIDI system enabled DJs to develop new techniques to provide musical entertainment in the dance clubs, superimposing music from records onto pre-produced, digitally recorded sound supports and blending all the sounds in innovative ways:

In so far as House music has often been constructed from digitally pre-recorded (sampled) snippets of sound-material, 'musicianship' in its most generally accepted sense is virtually nonexistent, and the genre is therefore relatively accessible to composers from a disc jockey's background. With a sampler, synthesizers and computer linked by a MIDI system, a multitude of musical 'voices' can be perfectly synchronized to a beat and programmed to enter the piece as required. [...] Operating a digital code rather than an electromagnetic tape allows very fast and easy editing of the material, which can be reversed, slowed down or speeded up as deemed appropriate. (Langlois, 1992: 231)

Yet if Rap and the new dance music - House and Techno - are clear illustrations of the way in which new digital technologies were rapidly being absorbed into music production and were involved in the recreation of musical styles and practices, they did not emerge in isolation from what was happening on the rest of the recorded popular music scene. In fact, throughout the 1980s and 90s, the use of digital technologies turned mixing, sampling and synthetically produced sounds into composition techniques that spanned all genres of music.

Music production frequently began to resort to recycling popular music tracks from other eras and appropriating them as raw material for the creation of new music. ${ }^{7}$ These processes

\footnotetext{
7 "Using sampling techniques, musicians and studio producers can effectively take sounds 'out' of their 'original' contexts and rework them into new pieces of music. Early examples of the use of sampling in the construction of 'new music' can be heard in the work of mid-1980s combo the JAMS, who later re-emerged as the KLF. The JAMS created tracks such as 'The Queen and I' that fused snatches of ABBA and Sex Pistols
} 
were explored with the aid of many different resources for technologically manipulating human and non-human sounds and for integrating purely synthesised sounds into musical composition. If from a strictly musical point of view these forms of composition led to various controversies, in terms of phonographic production they entailed new problems associated with the establishment of authorship and the awarding of copyright.

In addition to its repercussions on music production, the application of digital technologies to recording supports and equipment for reproducing music at the beginning of the 1980s gave rise to radical changes in the consumption of recorded music. Sony and Philips were the companies responsible for this application. They collaborated on the development of the first digital players and discs - the compact discs (CDs). The prototype for the system was presented by Philips to the phonographic industry in 1981, but it was not until 1982 that the first compact discs (CDs) went on sale in Japan and the United States, having been introduced into European markets in 1983 (Gronow and Saunio, 1999: 147212).

Philips and Sony then developed an aggressive promotion campaign in order to beat off their competitors and impose their compact disc system as the industry standard. One of the great advantages of the partnership between these two companies lay in the fact that they were immediately able to explore the combination of the new hardware and the software associated with it, i.e. the recorded music. The fact that Philips was the parent company of Polygram made this direct link between the introduction of new technology and the recorded music market possible, and this proved fundamental in illustrating the potential of the new equipment and supports.

The main advantages of the new digital technologies lay in the clean recorded sound and its reproduction, the extended recording time available on the new discs, the possibility of random playing of tracks and, above all, their greater resistance to wear and tear (Millard, 2000: 346-356). The main disadvantages lay in the difficulties inherent in assimilating the new technologies and in agents in the phonographic fields and markets adapting to them. In fact, their introduction required a rupture with the established formats and the need to renew the players and sound reproduction systems used by consumers. This implied a 
relatively high cost, at a time when cassette recorder systems, which were cheaper, were still winning over the public.

Even so, the new digital technologies proved immediately interesting, particularly for the dissemination of classical music. The lovers of this kind of music, normally demanding consumers who appreciate the technical qualities of the sound of recorded music, soon showed an interest in the new technologies. In addition, for the first time the increased capacity of compact discs allowed for uninterrupted listening of longer pieces of music, such as symphonies or major concerts.

Despite the positive reception from the world of classical music, it was only in the latter half of the 1980s that the sale of CDs became more popular and the market became attractive to publishers. In fact, during the first half of the decade, although the market for vinyl discs was in serious crisis, the market for audiocassettes was expanding significantly. It took time for the companies to realise the advantages of the new technologies and for consumers to recognise them, overcoming the uncertainties associated with the introduction of a new sound recording and reproduction system.

Once these hesitations had been overcome, CDs proved to be an excellent opportunity for the phonographic companies. It enabled them to re-issue many recordings from their back catalogues, by digitalising them and releasing them as compact discs. This helped to win over new generations of consumers ready to build up their own personal music collections, whilst also attracting consumers already committed to renewing their collection in the new formats. It also provided a justifiable opportunity for raising the price of CDs. These changes explain, to a large extent, the growth in phonographic markets during the latter half of the 1980s, at the end of which sales of CDs had clearly overtaken sales of vinyl records in the main markets (Gronow and Saunio, 1999: 147-212). ${ }^{8}$

Less than ten years after the introduction of the first compact discs and players, the first digital audio recording systems began to appear on the market: the Sony Digital Audio System (DAT), the Philips Digital Compact Cassette (DCC) and the Sony Mini Disc (MD). None of these supports and formats met with any success on the markets. This time, the failure of Sony and Philips to reach an agreement on the technological standard to be adopted led to

\footnotetext{
${ }^{8}$ This happened in the phonographic markets of North America, Europe and Japan, but as Peter Manuel (1993) and Roger Wallis and Krister Mälm (1984) show, peripheral markets depended on more economical technologies, mainly cassettes.
} 
incompatibilities between systems and strong market competition. The resistance of the phonographic companies to releasing music in these formats also helped weaken these technologies.

In general, the phonographic industry feared the unrestricted commercialisation of new digital recording technologies, due to the fact that they might lead to renewed opportunities for the unauthorised reproduction of phonograms. Piracy had become a major concern in phonographic fields following the popularisation of magnetic recording systems, and therefore the associations representing the North American market sector (in particular, the Recording Industry Association of America - RIAA) and the European market sector (represented by the International Federation of the Phonographic Industry - IFPI) made every effort to prevent the spread of digital recording technologies.

Despite the conservative attitude of the industry, the integrated development of computer and entertainment systems led to the introduction into the market of computerized devices that were capable of operating with digital codification systems for video, audio, text, animation and interactive schema. CD-ROMs were the first supports of this kind to appear, and could be played on the drive of any personal computer. They were followed by compact recordable discs (CD-R), a little later by rewritable compact discs (CDRW) and then by DVDs. These developments could not be controlled by the phonographic industry, and the devices for digitally recording phonograms became available on the domestic equipment markets at relatively low prices.

By the end of the 1990s the possibilities made available to consumers by the new digital technologies - acquiring a CD of recorded music, copying it onto the hard disc of a computer or onto another $C D$ - were increased by the innovations that had taken place in the sphere of information technology. These innovations followed the creation, in 1989, of a worldwide network providing communication between computers - the World Wide Web (WWW $)^{9}-$ and the appearance, in 1994, of the first commercial browser - Netscape.

In the latter half of the 1990s, technical and technological innovations exploiting the endless potential offered by the World Wide Web flourished and within a few years had radically transformed the mechanisms for distribution and access to recorded music, altering the face of phonographic markets.

\footnotetext{
9 The protocol establishing the Internet appeared in 1974, but the World Wide Web (WWW) was only established in 1989 (Kretschemer, Klimis and Wallis, 2001: 418).
} 
In 1993, Rob Lord and Jeff Patterson designed a kind of digital music archive in MP2 ${ }^{10}$ format, the Internet Underground Music Archive - IUMA, destined specifically for alternative and independent music. However, it did not succeed as an alternative to the traditional forms of music distribution due the operating conditions of the Internet and the still incipient development of codification systems for audio files. In 1995, Rob Glaser launched the Real Audio System, a device which compressed audio files and delivered them to Internet users. It was associated with the Real Player, a software program which, when installed on personal computers, could play audio and video files that had been compressed using the Real Audio System. In 1997, Justin Frankel helped to develop Winamp, a program which read music files codified in MP3 format and reproduced them on personal computers.

With the advent and rapid spread of the MP3, opportunities for circulating recorded music via the Internet opened up definitively and since then countless sites have emerged offering sound and image contents. One of the most famous was MP3.com, created by Michael Robertson in 1997. Initially devoted to providing information on the increasingly widespread MP3 music sites, it quickly became a music site itself, mainly storing the work of independent bands (Millard, 2000: 388-402). In 1999, Diamond Multimedia introduced the first portable MP3 player, the Rio PMP 300. Many other models followed, to the extent that, as Andre Millard suggests (2000:395), the MP3 player became the Walkman of the $21^{\text {st }}$ century.

The phonographic companies kept their distance from these processes. They continued to back the production of CDs, and especially the traditional forms of sales and distribution, although some began to sell CDs via the Internet. ${ }^{11}$

However, at the end of the 1990s, when new mechanisms began to be adopted for the physical distribution of digital information - broadband, cable optics, high speed modems offering greater speed and quality for the flow of information on the Internet, applications for the direct exchange of recorded music via the net emerged, namely peer-to-peer systems (P2P). The name Shawn Fanning became familiar to Internet users due to the fact

\footnotetext{
${ }^{10}$ The MP2, like the MP3, is a system for digitally codifying sounds. The MP3 began to be developed in 1985 by the Fraunhofer Institute for Integrated Circuits in Germany and was introduced in 1992. Its adoption as part of standard digital audio and video compression systems was defined by the Moving Picture Experts Group (MPEG) Layer3 in 1994 (Kretschemer, Klimis and Wallis, 2001: 419).

${ }^{11}$ Many adopted the Real Audio System to place small samples of the music from their albums online so that they could be listened to by internet users who had access to the Real Player. However, they did not make all the tracks from the CDs available. The complete set of tracks remained associated only with the discs as physical objects.
} 
that he developed this process through the Napster system, launched in 1999, which was designed to allow free and direct exchanges among music lovers.

P2P systems revolutionised access to recorded music, helping to create global audiences linked by the World Wide Web and able to share audio files with each other without any intermediaries other than the technical and technological devices and applications. Whilst other digital technologies already offered consumers the opportunity to control and manipulate music recordings, applications allowing for the direct exchange of music content provided them with infinite possibilities for accessing the private audio collections of other net users. Indeed, P2P networks are radically different from the traditional

client-server model, in which information flows from a centralized source (the server, a computer or group of computers that stores and distributes data) and its users (the clients, who request data from the server). Instead, P2P describes a decentralized network in which each computer has direct access to certain designated files stored on every other computer; the circulation of data among members of a network is known as file-sharing. (Katz, 2004: 161)

Given this context, the position of the phonographic companies was under serious threat. On the one hand, the new resources and network communications systems constituted a threat to their roles of selecting and diffusing musical works and to their sales and distribution structures. On the other hand, P2P systems destroyed the basic principles of intellectual property, offering unimaginable possibilities for the illegal use of phonograms and threatening control of the intellectual property rights distributed among the various agents in the value chain of the phonographic sector. To the threat of industrial piracy, strengthened by digital technologies, was now added a wealth of opportunities for illegal copying by consumers.

Thus, a whole series of possibilities opened up which radically changed the kinds of relationship consumers of music had with the world of recorded music and, with them, the conventions that had, for a long period of time, governed the definition of use values for this music. In the final analysis, these changes generated disagreements about the definition of the core objects of the phonographic industry, reflecting ambiguities similar to the ones that had marked the early years of the industry. In fact, the phonographic industry proved incapable of understanding and assimilating the process of the dematerialisation of recorded music, failing to keep up with the reinvention of the mechanisms mediating between creation and consumption. These mechanisms led to major changes in music culture, in the processes of establishing criteria for the recreational and aesthetic enjoyment of music, and 
in practices for using and manipulating this music. At the same time, they changed the conditions for creating, recording and distributing music, in the final analysis enabling a direct and reciprocal relationship to be established between creators and consumers.

Via the Internet, consumers are increasingly proving themselves to be music lovers, in the sense described by Antoine Hennion (Hennion, 2001). They can select music, choose performers, share preferences, justify their tastes and defend their criteria, argue choices, compare themes and performers, communicate with creators, compose their own musical selections... all in addition to being able to connect these activities to the sphere of creative practice, nowadays accessible through the link between software programs, production and sound recording equipment and musical instruments.

The Internet has increased and utterly transformed cultural socialization networks, practices of constructing musical taste and ways of relating to musical works (Hennion, 2005). In this sense, digital systems, the Internet, and in particular P2P systems have opened up a series of new possibilities for updating the order of inspiration in defining the value of phonograms.

In general, the changes that have taken place since the 1980 s - in terms of the various technological devices, composition processes, musical forms and content, market mechanisms and forms of consumer use - have radically altered a significant number of the conventions of the phonographic field, which embodied the orders of worth that presided over the functioning of the field. The new technologies have introduced acute uncertainties with regard to what had been defined as the specific object of the phonographic industry throughout its history, namely phonograms. Will they remain as discs? Or are these objects fated to disappear and finally give way to non-material protocols? The new forms of composing and creating music have altered the conventions established for works of music and their originality. In doing so, they have introduced many new issues regarding the definition of rights of authorship, which had been established in the early $20^{\text {th }}$ century, and the operating mechanisms of the civic order that presided over the coordination of phonographic activities in this sphere. The changes in market mechanisms, namely the emergence of systems of direct non-commercial and non-material exchange, threatened the conventional retail trading mechanisms and led to the invention of mechanisms for online trading. The calculation agreements for these new mechanisms are radically different from 
those employed in traditional trading, ${ }^{12}$ imposing changes in the production of the market value of phonograms. Even so, direct, non-monetary exchange between consumers continues to generate uncertainties in this area. Changes in the use consumers make of phonograms, which extends beyond listening to records to include, in general terms, reproduction, sharing and re-creation, have altered the conventions of the music culture underlying phonographic consumption and have created great controversy over market rules, the conventions of musical ownership and the actual convention regarding the distinction between creator, work and consumer, a convention that is one of the keystones of modern cultural fields.

\section{Conclusion}

To conclude, I intend to return briefly to the opening idea in this essay, in which I expressed my perplexity at the superficial treatment often given to the culture industries in sociological writings. What the history of the phonographic industry shows us in this respect is that the culture industries constitute organisational fields that have a high level of complexity. Several principles and logics operate within them: the technical-industrial logic and the market logic, traditionally associated with the sphere of economic activities; the logics of inspiration and fame, associated with the cultural and artistic spheres; and the civic logic, related to public regulation. The complexity of the cultural industries field results from the coexistence of these diverse logics and coordination systems which, although incommensurable, must coexist within the organization and dynamics of the field. This coexistence is essentially based on numerous established conventions which enable the systems to operate and alternate during the course of activities.

The periods in which new spheres of activity emerge and develop, as was the case in the last two decades of the $19^{\text {th }}$ century and the first decades of the $20^{\text {th }}$ century, a time when phonographic activities were established and perfected, enable us to perceive the principles mobilized by these fields of action. However, this perception becomes particularly acute in times of crisis, such as the one experienced by the phonographic industry in the past two decades as a result of the redefinition of various conventions, whether technical-industrial, cultural, market or even civic. The transformation of these conventions has had multiple consequences for the coordination of activities and the structure of the field, giving rise an

\footnotetext{
${ }^{12}$ On the concept of markets as calculative collective devices, see Callon \& Muniesa, 2005.
} 
atmosphere of doubt and uncertainty with regard to the legitimacy of the established justification regimes. These uncertainties have proved particularly sharp since they have unleashed disputes not only over the objects and material devices associated with the phonographic universe, but also over the definition of the relevant actors, the tests for evaluating their respective worth and defining hierarchies and, above all, over the actual principles of worth underlying the various activities. There is a multitude of possible foci of uncertainty that abundantly show the impossibility of reducing cultural industry fields to the classic dichotomy between economics and culture and illustrate the density of processes that have yet to be studied more closely.

Translated by Sheena Caldwell

Revised by Teresa Tavares

\section{References}

Bennett, Andy (1999), "Hip hop am Main: The localization of rap music and hip hop culture," Media, Culture \& Society, 21(1), 77-91.

Bennett, Andy (2001), "Contemporary Dance Music and Club Culture," in Andy Bennett, Cultures of Popular Music. Buckingham/Philadelphia: Open University Press, 118-135.

Boltanski, Luc; Thévenot, Laurent (1991), De la justification. Les économies de la grandeur. Paris: Éditions Gallimard.

Boltanski, Luc; Thévenot, Laurent (1999), "The Sociology of Critical Capacity," European Journal of Social Theory, 2(3), 259-377.

Bourdieu, Pierre (1996), The Rules of Art: Genesis and Structure of the Literary Field. Trans. Susan Emanuel. Stanford: Stanford University Press [Originally published in French in 1992].

Callon, Michel; Muniesa, Fabian (2005), "Economic Markets as Calculative Collective Devices," Organization Studies, 26(8), 1229-1250.

Chanan, Michael (1995), Repeated Takes. A Short History of Recording and Its Effects on Music. London/New York: Verso.

DeNora, Tia (1995), "Beethoven et l'invention du génie," Actes de la Recherché en Sciences Sociales, $110,36-45$.

Fligstein, Neil (1996), "Markets as Politics: A Political-Cultural Approach to Market Institutions," American Sociological Review, 61(4), 656-73.

Fligstein, Neil (2001), The Architecture of Markets. An Economic Sociology of Twenty-First-Century Capitalist Societies. Princeton/Oxford: Princeton University Press.

Fradique, Teresa (2003), Fixar o movimento: representações da música rap em Portugal. Lisbon: D. Quixote.

Frith, Simon (1988), "The Industrialization of Music," in Simon Frith, Music for Pleasure. Essays in the Sociology of Pop. Cambridge: Polity Press.

Hennion, Antoine (1989), "An Intermediary between Production and Consumption: The Producer of Popular Music," Science, Technology \& Human Values, 14(4), 400-424. 
Hennion, Antoine (2001), "Music Lovers. Taste as Performance," Theory, Culture \& Society, 18(5), 1-22.

Hennion, Antoine (2005), "Pragmatics of Taste," in Mark D. Jacobs and Nancy Weiss Hanrahan (eds.), The Blackwell Companion to the Sociology of Culture. Malden, MA: Blackwell Publishing, 131-144.

Katz, Mark (2004), Capturing Sound. How Technology Has Changed Music. Berkeley/Los Angeles/London: University of California Press.

Kretschmer, Martin; Klimis, George Michael; Wallis, Roger (2001), "Music in Electronic Markets. An empirical study," New Media \& Society, 3(4), 417-441.

Langlois, Tony (1992), "Can you feel it? DJs and House Music Culture in the UK," Popular Music, 11(2), 229-238.

Maisonneuve, Sophie (2001a), "De 'la machine parlante' à l'auditeur. Le disque et la naissance d'une nouvelle culture musicale dans les années 1920-1930," Terrain, 37 - Músique et émotion. Consulted on 12 July 2007 at http://terrain.revues.org/document1289.html.

Maisonneuve, Sophie (2001b), "Between history and commodity: The production of a musical patrimony through the record in the 1920-1930s," Poetics, 29(2), 89-108.

Maisonneuve, Sophie (2002), "Le disque et la musique classique en Europe, 1877-1949: l'invention d'un médium musical, entre mutations de l'écoute et formation d'un patrimoine." PhD dissertation, European University Institute, Florence, Italy (mimeo).

Manuel, Peter (1993), Cassette Culture. Popular Music and Technology in North India. Chicago/London: The University of Chicago Press.

Millard, Andre (2005), America on Record. A History of Recorded Sound. New York: Cambridge University Press.

Gronow, Pekka; Saunio, Ilpo (1999), An International History of the Recording Industry. London/New York: Cassell.

Powell, Walter W.; DiMaggio, Paul (1991a), "The Iron Cage Revisited. Institutional Isomorphism and Collective Rationality in Organizational Fields," in Walter W. Powell \& Paul DiMaggio (eds.), The New Institutionalism in Organizational Analysis. Chicago: University of Chicago Press, 1-38.

Read, Oliver; Welch, Walter L. (1976), From Tin Foil to Stereo. Evolution of the Phonograph. Indianapolis/Kansas City/New York: Howard W. Sams \& Co., Inc; The Bobbs-Merril Co., Inc.

Rose, Tricia (1994), Black Noise. Rap Music and Black Culture in Contemporary America. Hanover, $\mathrm{NH} /$ London: Wesleyan University Press.

Théberge, Paul (1997), Any Sound You Can Imagine. Making Music, Consuming Technology. Hanover, $\mathrm{NH} /$ London: Wesleyan University Press.

Thévenot, Laurent (2001), "Organized Complexity. Conventions of Coordination and the Composition of Economic Arrangements," European Journal of Social Theory, 4(4), 405-425.

Thévenot, Laurent (2002), "Conventions of Co-ordination and the Framing of Uncertainty," in Edward Fullbrook (ed.), Intersubjectivity in Economics. Agents and Structures. London/New York: Routledge, 181-197.

Wallis, Roger; Mälm, Krister (1984), Big Sounds from Small Peoples. The Music Industry in Small Countries. London: Constable.

Weber, William (1989), "Mentalité, tradition et origines du canon musical en France et en Angleterre au XVIIle siècle," Annales ESC, 4 (July-August), 849-873. 